\title{
Multi-Criteria Assessment of Public Rail Companies
}

\author{
Gerard Colson \\ University of Liège \\ Mapapa Mbangala \\ University of Liège \\ I.S.C.-Kinshasa (DRC)
}

The achievements of ten African public rail companies are compared with each other using the multicriteria methods ELECTRE I, PROMOTHEE II and JUDGES. The 25 first-level criteria retained are first grouped into 8 families, each capturing a second-level objective. The efficiency of the service is assessed by a technical-economic evaluation function grouping the first 4 families. Its efficiency is measured by an evaluation function involving the other 4 families made up of traditional financial ratios that are likely to capture the management balance and the origin of financial resources. The authors conduct longitudinal and cross-sectional analyses of the data by comparing the results generated by ELECTRE and PROMETHEE. The JUDGES software successively shows the tree of correlations observed between the 8 families of criteria, and the rank distributions of firms according to 8 families. From a methodological point of view, this work is a variant of ELECTRE I and checks the relevance of multi-criteria methods in terms of ranking the performance of public companies.

\section{INTRODUCTION}

Measuring the efficiency of public enterprises is by nature multi-criteria because of the dual mission entrusted to them: being effective in their mission of public service and economic development of the country while remaining efficient in their management and use of resources. More often, these two missions present contradictory aspects. The aim of this work is to use multi-criteria methods to compare the overall performance of African railway companies.

In Africa, railway companies contribute to economic development, both by carrying goods, particularly raw materials, to ports, and by transporting passengers (two activities reflected in the first two families criteria). To study their overall technical efficiency, we have constructed 3 synthetic criteria that form a family, based on data that are not broken down into freight and passenger traffic. The last family of criteria measures the integration of the railway into the country's economy. Four families (Freight, Passenger, Global and Economy), comprising 14 criteria, will therefore be used to determine the general concept of network efficiency via a technical and economic evaluation function. The other notion of efficiency is grasped via four other families of criteria, two to reflect productivity and costs and two to reflect management balance and the origin of financial resources. Grouping together the 11 criteria from the last four families of criteria, we construct an evaluation function based on financial ratios, or substitutes as needed. 
Our methodology is hence based on a hierarchical multi-criteria analysis at 3 levels: 25 criteria, 8 families, 2 functions. Section II presents the analysis scheme and deals with the choice of methods, scales, criteria and thresholds. In Section III, we compare nine railways, one per country, using data from the period 1975-1990. The multi-criteria methods chosen are ELECTRE I-F ${ }^{2}$ and PROMOTHEE II as well as JUDGES. After various longitudinal and cross-sectional analyses, we conclude in Section IV.

\section{METHODOLOGY OF ANALYSIS}

The choice of criteria, methods, scales and thresholds for analysis depends on the problem and the data. Initially, we choose not to weigh either the criteria or the families since our goal is comparative analysis and not decision-making, where the weighting of decision-makers should be obtained.

The issue of public enterprises requires that their performance be evaluated both on financial criteria and on the objectives of their public service mission.

The latter often contradict the former. Moreover, it is impossible to define the optimal benchmark company for the achievement of all the financial and general interest goals involved. Hence the need to interpret our "Good" or "Bad" qualifications in all relativity.

Given the difficulty of collecting them on the spot, the financial data are reduced to a set drawn from the annual operating accounts covering 11 years: (1980-90) for 7 railways, 1 per country (Congo, Cameroon, Kenya, Mali, Senegal, Zaire and Zimbabwe). We were also able to gather information on the main physical characteristics of rail transport inputs and outputs, together with some useful economic data covering a period of 16 years (1975-90) for the following 9 countries: Benin, Cameroon, Congo, Kenya, Mali, Mozambique, Senegal, Zaire and Zambia.

A first transformation of the data resulted in a set of ratios, which frees us from the inflation effect affecting local currencies. The initial measurement scales are therefore ratio scales. Figure 1 provides a synoptic view of our analytical approach.

Starting with a set of ratios (not provided in this article), which enables us to establish performance according to technical, economic and financial criteria, we then arrange these criteria into 3 levels of analysis. The most disaggregated level consists of classic ratios such as traffic shares, network densities, , average routes expressed in technical units, and productivities in values, costs and financial ratios in general $^{3}$.

At the 2 nd level, we group these ratios into families, or valuation approaches, based on 2 to 4 criteria. These families can be assimilated to "judges" who evaluate the "options" or "shares" considered in accordance with a multi-criteria approach. At this stage of the analysis, we perform an annual aggregation by family of the basic criteria, using ELECTRE I and PROMETHY II. Using the direct and recent cores of ELECTRE I, we will classify the enterprises (designated by the name of their country) into four groups: "good" (G), "bad" (B), "average" (A), and "incomparable" (C), which we will codify for aggregation over the analysis period. The families themselves are grouped into two evaluation functions. The technoeconomic function addresses the general objective of production efficiency, while efficiency, in the sense of cost minimization, is captured in the financial function. The latter function also reflects the management balance and the origin of the financial resources of companies, including the State with its public service subventions. 
FIGURE 1

\section{DATA ANALYSIS DIAGRAM}

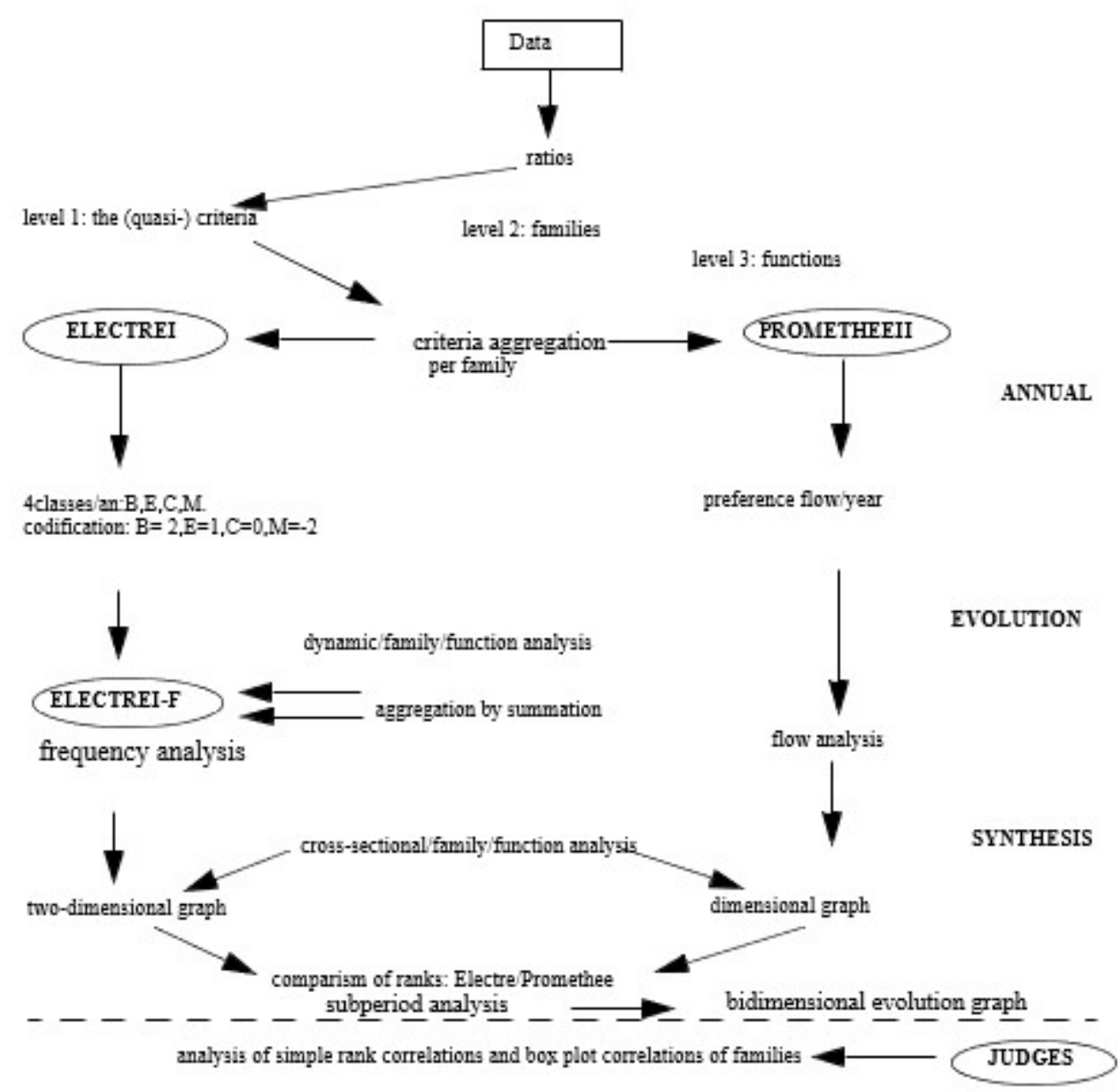

Table 1 synthetises the criteria, families and functions. A central column indicates the direction of preference $(\max$ or $\min )$ and the right-hand column, the "q" thresholds, marking the limit between indifference and preference. Indeed, we used quasi-criteria everywhere, the thresholds being chosen in such a way that performances judged to be significantly different on one criterion leave two companies tied in their ranking on that criterion. ${ }^{4}$ The inclusion of pseudo-criteria is not justified here because of the ratio scales chosen. Tables 2 and 3 will allow a dynamic analysis of the evolution of families and functions on the basis of the codification of the 4 classes resulting from the annual analyses.

ELECT I. At the bottom of these same tables, we have proceeded to a simple count of the frequencies of belonging of the different countries to each of these classes. We thus obtain a synthesis of the frequencies giving the relative position of the performances of the public enterprises studied.

The unorthodox use of ELECTRE I in its new form, ELECTRE I-F, which leads to a visualization of the positioning and ranking of performances, naturally called for a control of this ranking by a method destined to multi-criteria ranking. This is why we followed a parallel approach using PROMETHEE II, in an annual aggregation of criteria by family which generates annual preference flows, a dynamic analysis of the flows by family and by function, a summation of these flows to also lead to the synthesis analysis and the two-dimensional graph. Comparison of the results of the two methods shows very similar rankings, the few differences can be explained by the difference in the nature of the calculations made: in ELECTRE I$\mathrm{F}$, we carry out a group classification and a frequency analysis, thus combining a qualitative and a 
"frequency" approach, while PROMETHEE II works on a valued graph to draw up flows that will be interpreted and then summed up. Each of the two approaches of analysis brings its own light while preserving an overall coherence.

TABLE 1

\section{SET OF CRITERIA PRIORITIZED IN 3 LEVELS}

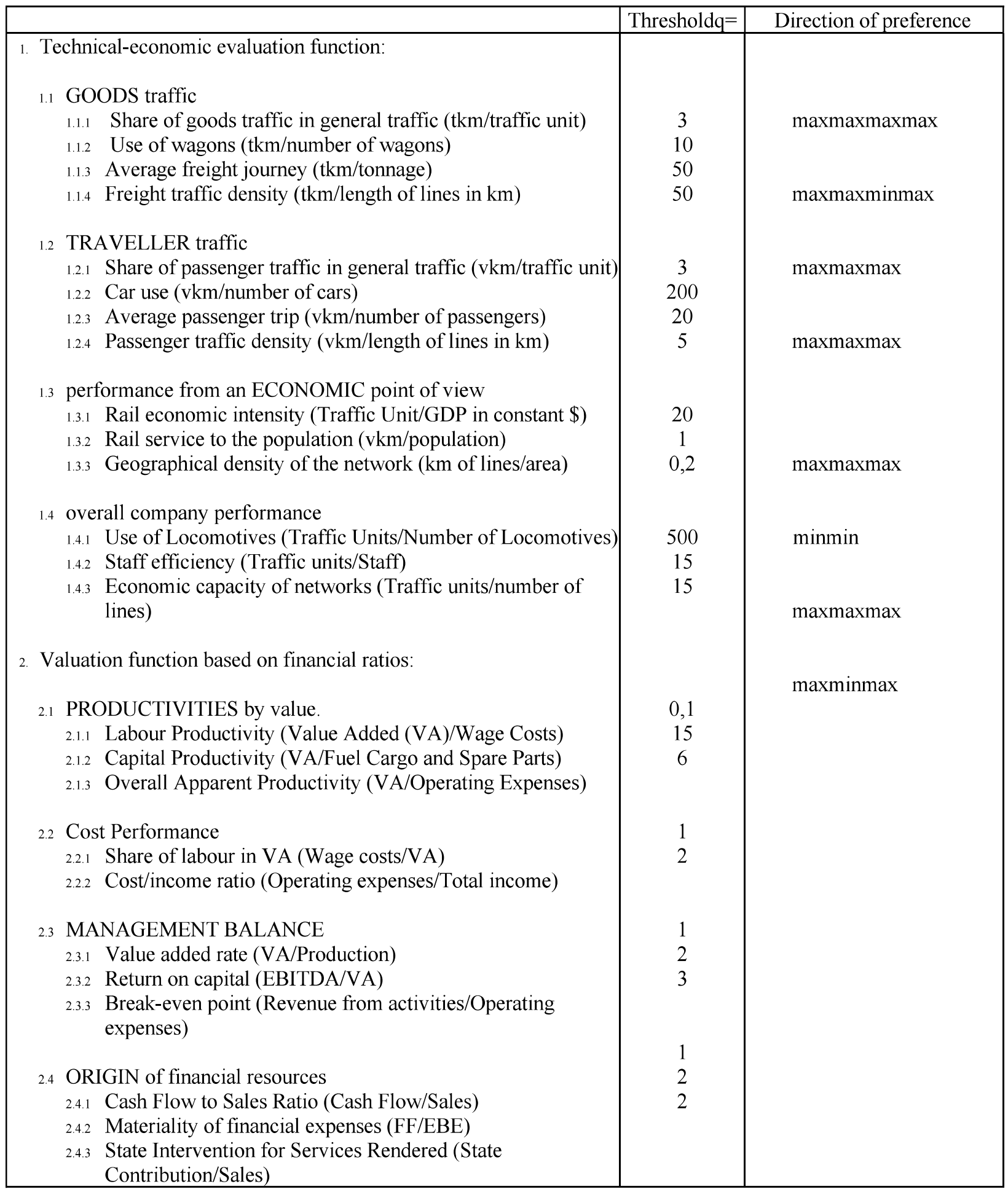




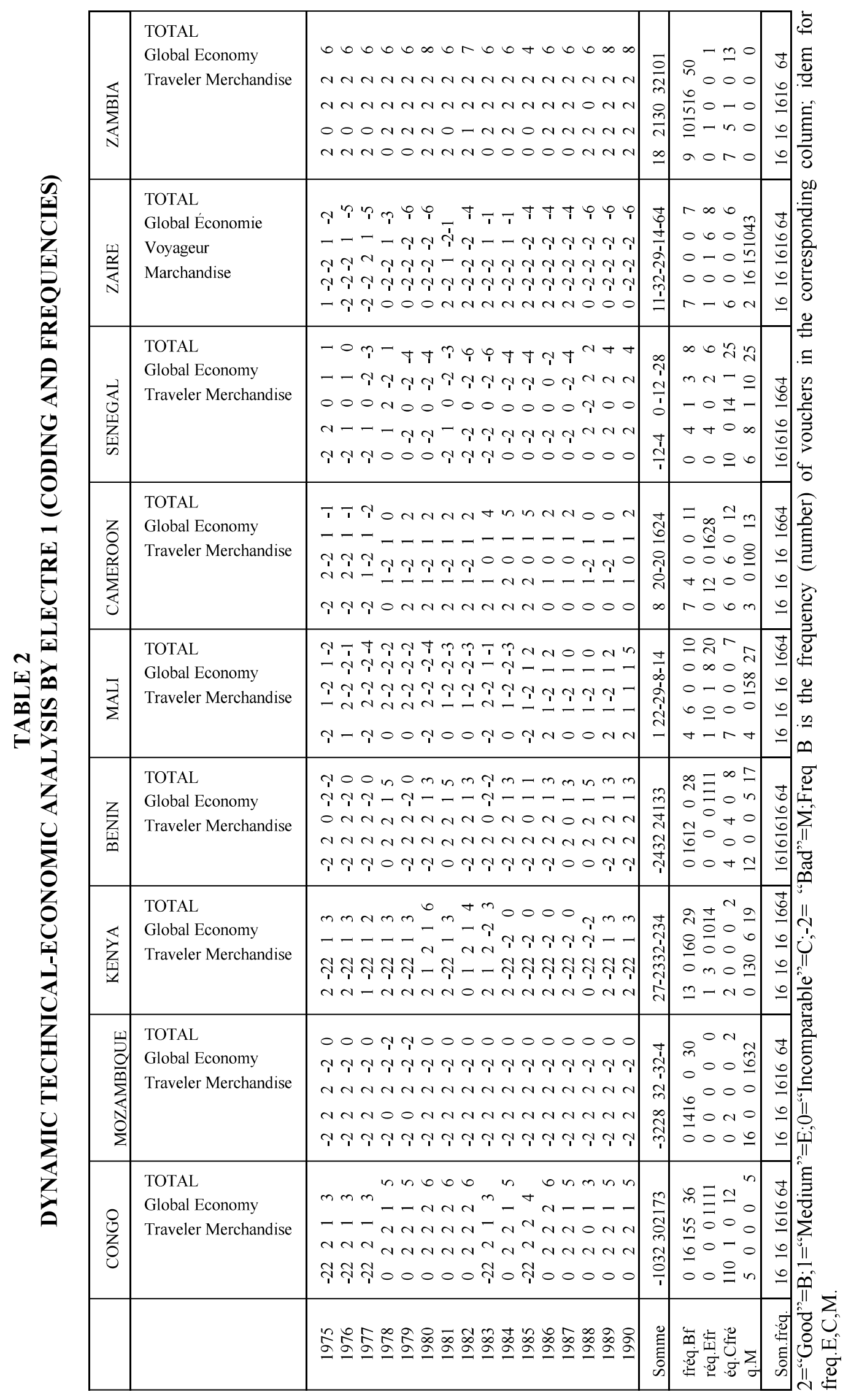




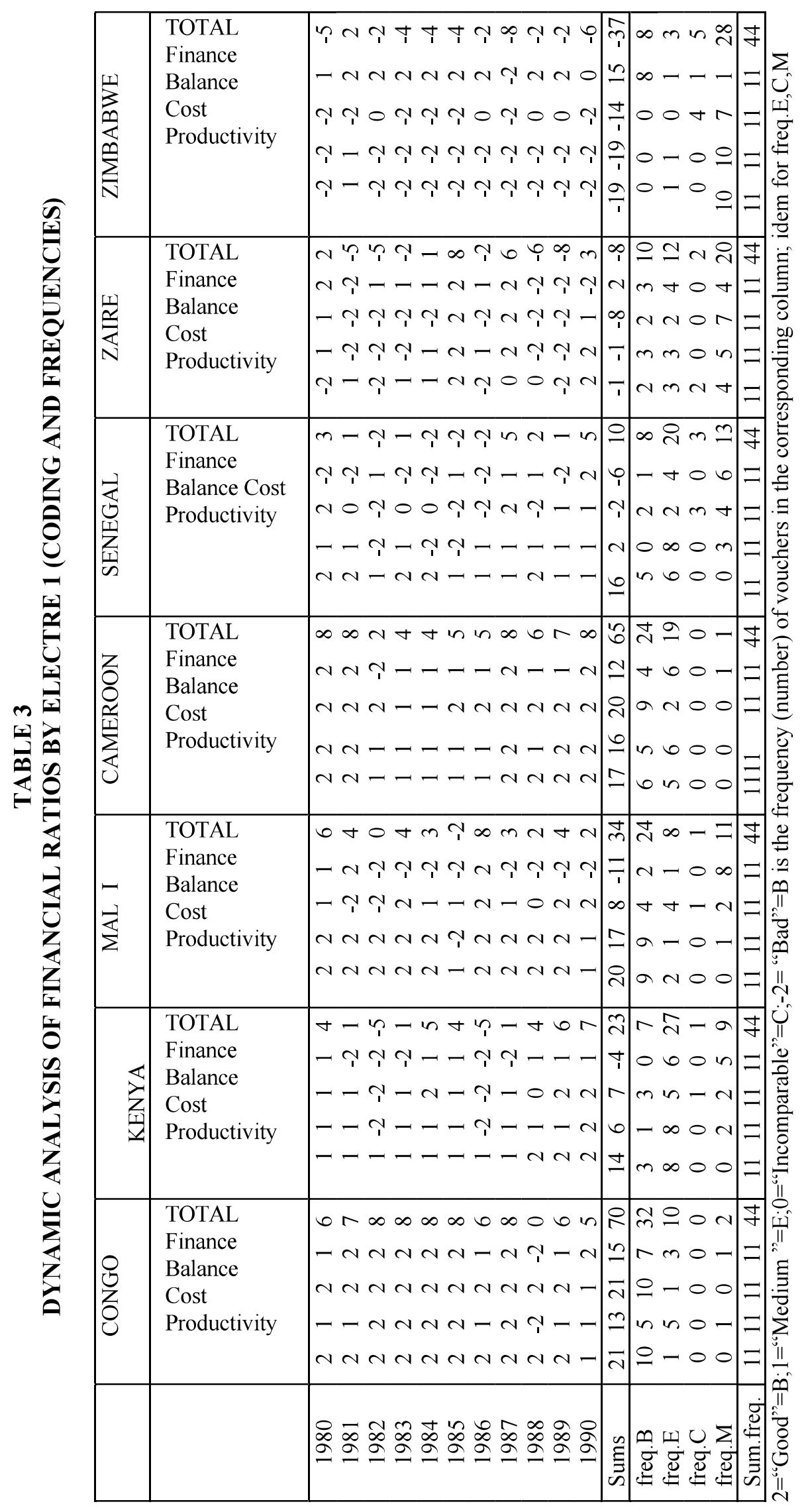


To conclude, we complete the analyses of this scheme by a study of the correlations among the families of criteria selected and we create a picture of the rank distribution of the companies, using the JUDGES method.

\section{APPLICATION OF THE ELECTRE, PROMETHEE AND JUDGE METHODS}

\section{Electrei}

Dynamic Analysis of Business Performance

Tables 2 and 3 show the progress of the rankings by family of criteria for the nine countries included in the techno-economic analysis and the seven countries in the analysis of financial ratios. In order to arrive at these results, the ELECTRE I method is implemented in the following way: in each family and for each year, the countries are compared two by two, using first a concordance threshold of 0.75 . . We do not use a discrepancy threshold because, from the point of view of our analysis, there is no reason to preclude an over classification on the basis of poor performance on a criterion and, moreover, the introduction of a nondiscrepancy test would distort the validation comparison with PROMETHEE II which does not have one.

The Venn diagram in Figure 2 shows the procedure for classifying countries into four groups of countries carried out annually per family using ELECTRE I:

FIGURE 2

FOUR CLASSES OF "SHARES" ACCORDING TO ELECTREI

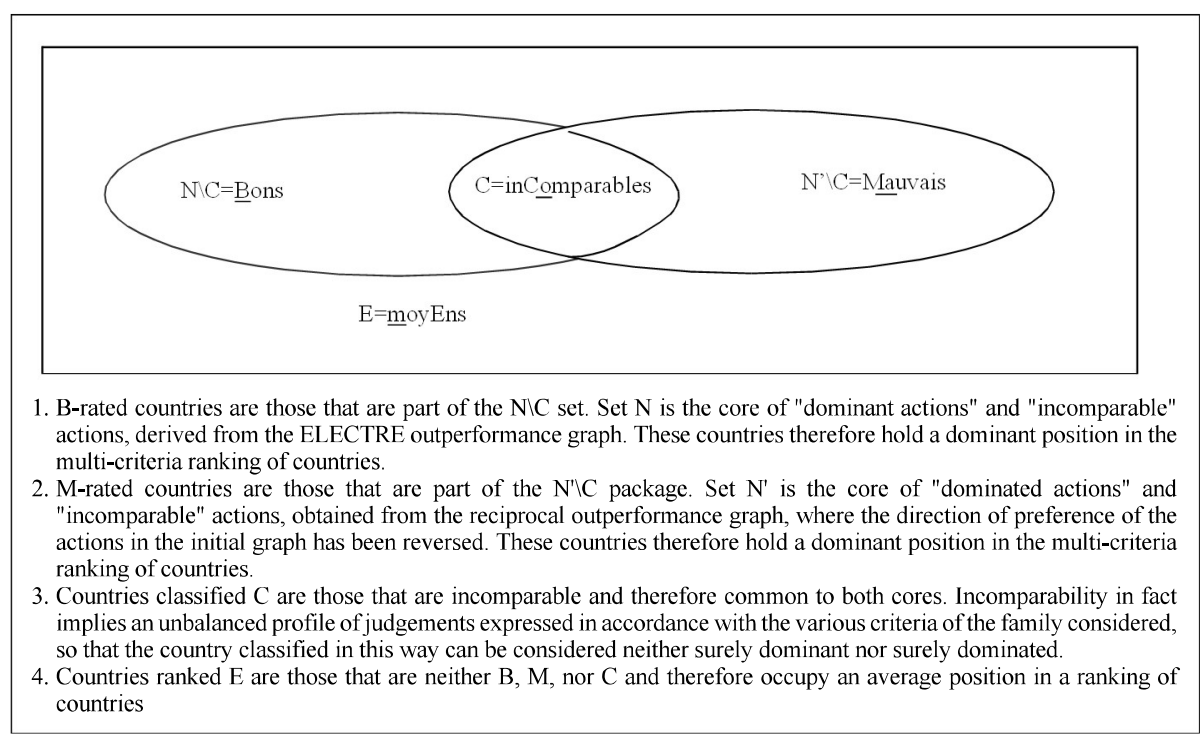

In order to simplify the language, we consider countries ${ }^{5}$ that are classified in B as having a good family performance, more briefly as "good", and we give them a score of 2. Similarly, we consider as "bad" countries classified in $M$ and give them a -2 rating. A rating of 1 is assigned to E-ranked payees, as they necessarily have a multi-criteria performance intermediate between "good" and "bad", while a neutral rating of 0 is assigned to "incomparable" payees.

A first finding concerns the insensitivity of the results of the two tables to variations in the concordance threshold. We have indeed checked this insensitivity by varying this threshold in steps of 0.1 between 0 and 1 without noting the slightest downgrading of countries. This suggests that our results are very reliable and that the companies examined are highly differentiated from each other.

This quantification of classes B, E, C, M allows us to expand on ELECTRE I, whose primary purpose is to select shares, with a frequency analysis that will rank the companies examined. This classification is 
carried out by considering the results longitudinally, i.e. over time, and transversally, i.e. in synthesis over all the periods of data analysis. To this end, we carry out five types of sums or counts per period, per family and per country, with annual individual scores. This procedure is the heart of our ELECTRE I-F version.

1. A general amount ("sum") of the scores in a column serves as a synthetic indicator of the multicriteria performance of the company in question in relation to other companies over the period under consideration and the envisaged family.

2. "B freq", the number of "2" in the column, is the synthetic indicator of the company's ranking among the "good". A high score likely means a good performance over a large part of the period and for the family being considered.

3. "E freq.", the number of "1" in the column, is an indicator of average performance.

4. " freq. C", the number of "0" in the column, will denote the existence of "unbalanced profiles" within the family of criteria under consideration.

5. A high frequency of "-2" in a column ("Freq. M") is a sign of poor family performance for the company in question.

In addition, for each country, the horizontal addition of annual family scores, or frequencies (at the bottom of the table), enables an evaluation of the country's performance according to the function under consideration. As an example, reading the line of sums shows that "Congo" has an overall technicaleconomic score of 73, resulting from a poor performance (-10) in the Merchandise family, more than compensated by its good performance in the other 3 families $(32,31,21)$. Frequency analysis reveals that the presence of 11 "bad" qualifications over the period 1975-1990 explains the country's poor score for the Merchandise family, while the almost constant presence of "2" in the Travellers and Economy columns indicates the good performance of the Congolese company during this period and for these two families.

Interpretation of company classifications in accordance to ELECTREI-F

Tables 4 and 5 present two types of company rankings. The first ranking, in italics, is based on the compensatory indicator that is the sum of the annual scores over the period. The ranking that emerges reflects the compensation between good scores $(+2$ and +1$)$ and bad scores $(-2)$ over the period. 


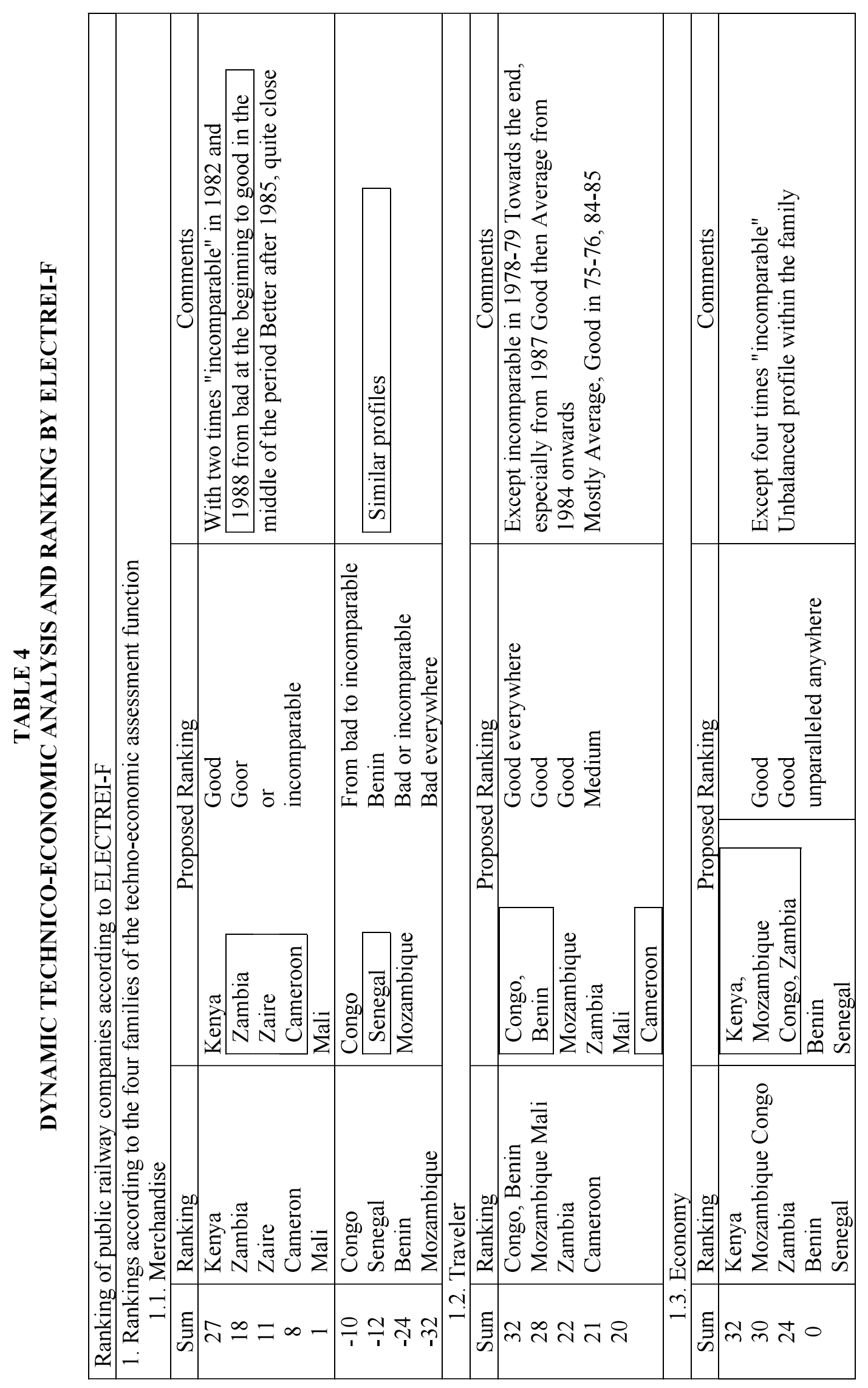

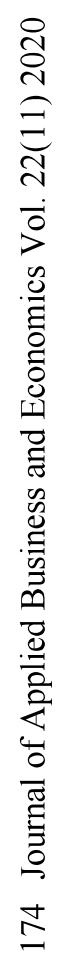




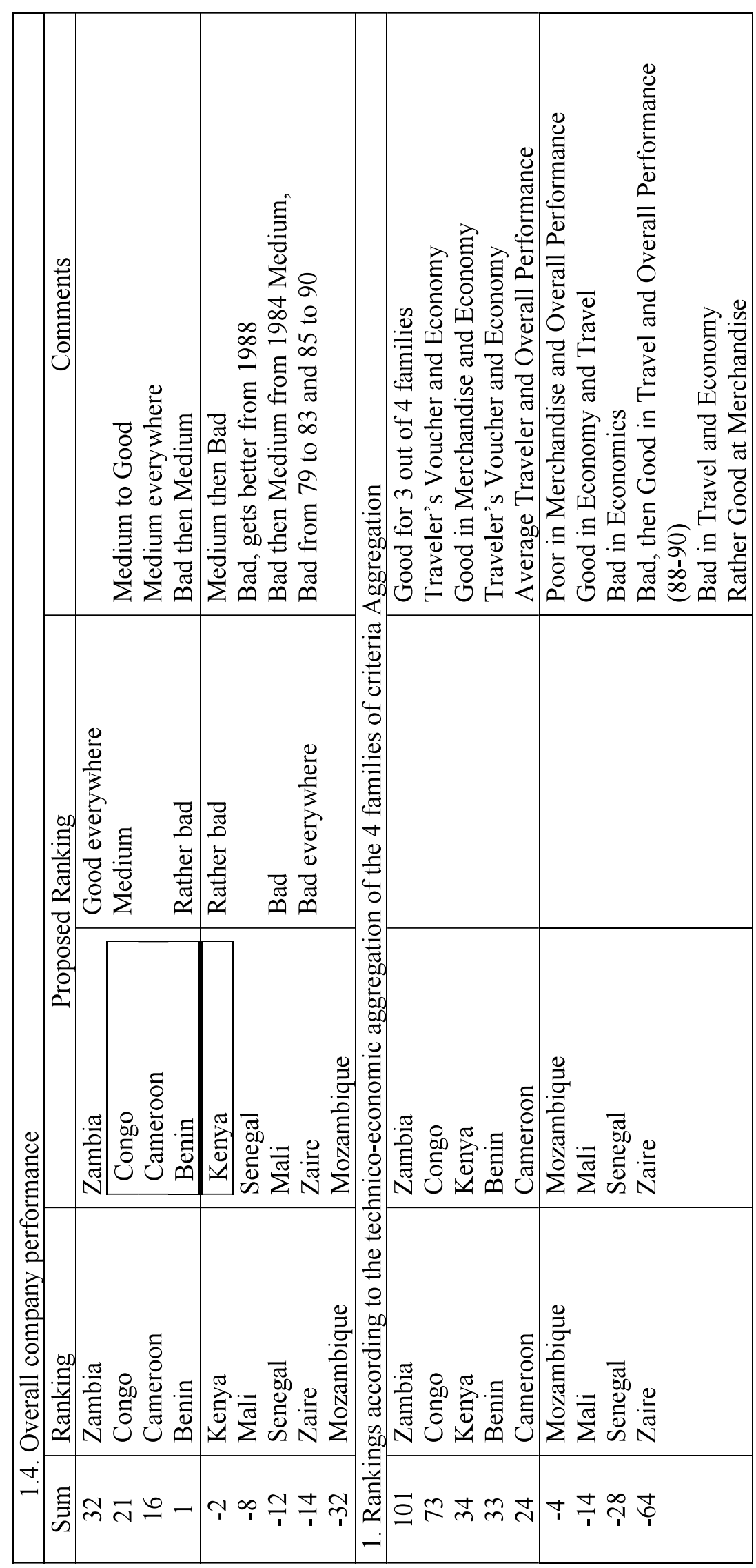

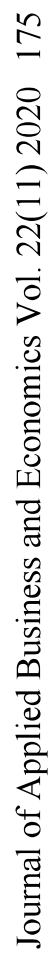


The classification suggested in the third column of these tables is, however, finer, although rarely different from the first one. This ranking is the result of a qualitative comparison of the respective frequencies of the "B", "E" and " $\mathrm{M}$ " ratings, essentially, with "C frequency" being used more to locate unbalanced intra-family profiles.

Firstly, a possible division into two groups can be observed: countries dominating the others with a positive score of the sum of periods and dominated countries with a negative score. Within these two groups, one can distinguish "good", "average", "bad" sub-groups with nuances such as good everywhere or good to average, etc. The comments column shows the sailing events of the period. For example:

1. From a technical and economic point of view and for the 1975-90 analysis period, the group of countries: Zambia, Congo, Kenya, Benin, clearly dominates the Senegal and Zaire group. Of the three remaining countries, Mozambique has the most unbalanced family profile to the extent that an ELECTRE I analysis applied to families would classify it as "incomparable". Cameroon and Mali have quite different profiles, the former being rather average and the latter showing some temporal volatility. Zambia, which comes first, is not uniformly good for all four families: while it is uniformly good over the period according to the "Economy" and "Overall Business Performance" families, it has periods of incomparability with the other two families, from 76 to 77 and from 83 to 86 respectively for the two "Traveller" and "Merchandise" families. Zaire, on the other hand, at the bottom of the pack, is "bad" in "Traveller" and "Economy" but is "good" in "Merchandise" from 81 to 87 and its overall performance is mostly poor. These two examples demonstrate the extent to which a multicriteria analysis makes it possible to nuance judgments that would be too brutal in synthesis.

2. According to the viewpoint of financial ratios and for the analysis period 1980-90, the group of countries Congo, Cameroon, Mali clearly dominates the group of the two countries Zaire and Zimbabwe, while Mali, Kenya and Senegal form a "rather average" group. Business in the Congo is really good everywhere and in all "financial" families except in 1988, an exceptional year. This company was therefore very well governed in the 1980s. The Zimbabwean company, on the other hand, has poor financial ratios apart from "source of funds". The explanation lies in the considerable amount of money it obtains from the State of Zimbabwe, without any doubts to support this much-sought-after public service enterprise, which deteriorates its ratios. 


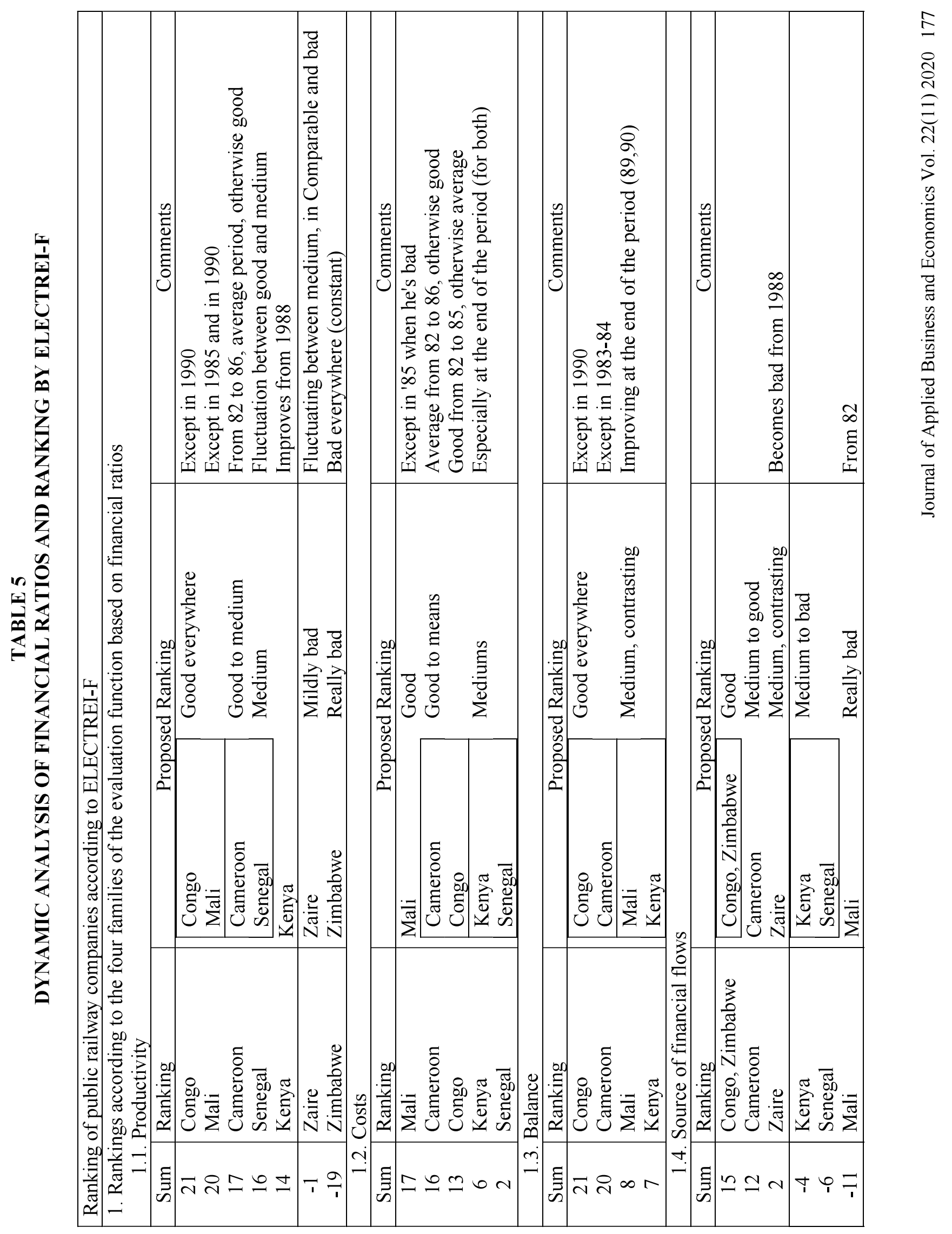




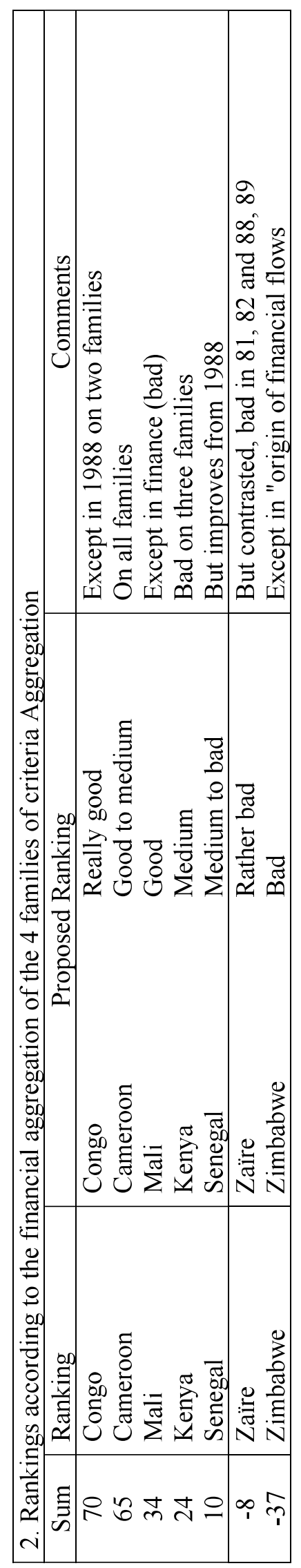

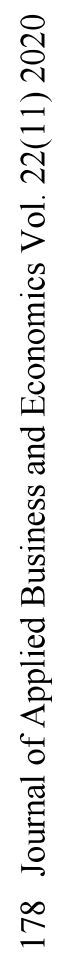




\section{Ranking of Companies According to ELECTRE's Two Evaluation Functions I-F}

The purists of ELECTRE I will be surprised that we continue to use the scores obtained with this method to arrive at a ranking of countries along two coordinated axes. As our alternative method of counting the frequencies of individual annual scores turned out to be very informative and more transparent than ELECTRE II, we have persevered in this direction to obtain a two-dimensional overview of the countries analysed

Two difficulties awaited us. First, the periods of analysis are unequal for the two technical-economic and financial themes, then the list of countries also differed: only six countries are common to both analyses. The latter six countries therefore score on both axes, while Zimbabwe is on the financial axis alone and Zambia, Benin and Mozambique are positioned on the techno-economic axis alone. The 16 years of the technical-economic analysis, compared to the 11 years of the financial analysis, imply a greater dis- persion of countries along the $\mathrm{x}$-axis than along the axis orderly. This scaling effect had to be kept in mind in our interpretation.

In order to facilitate a synthetic reading of the cross-criteria analysis, we have made a graphical representation of each company's position in the plan. We have associated each country with its ranking in relation to the others both at the aggregate level and within each family of criteria. For example, Congo took 2 nd position according to the techno-economic aggregation and 1st position according to the financial axis, which was translated by the vector $(2,1)$; it took $1 \mathrm{st}, 3 \mathrm{rd}, 1 \mathrm{st}, 2 \mathrm{nd}$ position respectively for the financial families: "Productivity, Cost, Equilibrium, Origin of flows"; it took respectively the 5th, 1st, 2nd position for the Technico-economic families: "Merchandise, Traveller, Economy and Global" so that the vectors ( 1 , $3,1,2)$ and $(5,1,1,2)$ were associated with it. The maximum possible rows are 9 for the first axis and 7 for the second.

Positive or negative signs of the scores made it possible to rank the companies as "dominant" or "dominated": positioning a company in the second quadrant means a negative score in "technicaleconomic" and a positive score in "finance", so that this company is on average dominated on the first axis and dominant on the second.

This type of representation is instructive. As an example, we observed that:

1. The Congo, Cameroon, Kenya group, located in the first quadrant, is dominant on both axes and is opposed to the Zairean company which is dominated on both axes, but especially on the Technico-economic axis. Mali and Senegal, in the second quadrant, are dominated in technoeconomic terms but remain dominant in finance, with Senegal only slightly so. When considering one axis at a time, thus including the countries listed on a single axis, Zambia was well ahead from a technical-economic point of view and Zimbabwe was well behind on the financial axis.

2. The Congo company largely outperforms other companies, with the exception of Zambia, which has a position of technical and economic leadership. In terms of multi-criteria and multijudge effectiveness, Congo and Zambia are the only two countries that are certainly effective.

3. Within each evaluation function, we have defined "effective countries " i.e. countries that are not dominated on at least one of the families of criteria. Congo, Cameroon, Mali and Zimbabwe are efficient in terms of finance. c Congo because of its rank 1 on "productivity and balance" families, Mali for the "cost" family alone and Zimbabwe in "origin of resources". In technoeconomic terms, Zambia is efficient because of overall efficiency, Congo because of "travel and economy", Kenya because of "commodity" and Mozambique because of "economy". Cameroon is a typical example of the shining second non-efficient, at least in financial terms. Senegal and Zaire are also ineffective. Benin without financial ratings cannot be said to be globally effective or inefficient, but it is inefficient on the first axis.

\section{PROMETHEEII}

Here we use a methodology which is similar to that of the previous section to build the cross-sectional and longitudinal (dynamic) analyses of preference flows constructed by the PROMETHEE II method. In 
each family and for each year, the countries are therefore compared two by two by elaborating the net flows of PROMETHEE II. It should be recalled that the essential contribution of this method compared to the ELECTRE I and II methods is the use of a valued preference graph, which leads to a more "graduated" evaluation of the actions. Tables 6 and 7 correspond to Tables 2 and 3 of the ELECTRE analysis, except that the results are net flows of convenience and are therefore more nuanced than our coding applied to the annual ELECTRE I results.

The respective sums at the bottom of the columns of the families allow us, as in ELECTRE, a transversal synthesis analysis, while the study of the annual flows permits a dynamic analysis corresponding to that of ELECTRE I. Given the great convergence of the results of the two dynamic analyses by ELECTRE and PROMETHEE, we will simply interpret, in parallel with those of ELECTRE I-F, some results of the cross-sectional analyses.

\section{Cross-Cutting Analysis of Technical-Economic Results}

Comparison of ranks achieved with PROMETHEE and ELECTRE:

1. Overall, i.e. in aggregated technical-economic terms, the ranking is identical with both methods, with the exception of the downgrading of Cameroon by ELECTRE, which puts it in 5th place, whereas PROMETHEE places it in 3rd place ahead of Benin and Kenya.

2. Within the aggregated assessment function, the PROMETHEE and ELECTRE rankings are very close, the maximum downgrading found is two ranks for a family.

3. In terms of technical-economic efficiency, the results are similar with both methods, with the difference that the Congo is more efficient only by the "Traveller" family, becoming second instead of first in Economy. The four effective countries are Zambia, Congo, Kenya and Mozambique. 


\begin{tabular}{|c|c|c|c|c|}
\hline \multirow{2}{*}{\multicolumn{2}{|c|}{ 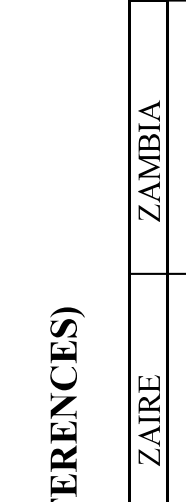 }} & $\begin{array}{l}\text { TOTAL } \\
\text { Global } \\
\text { Economy } \\
\text { Traveler } \\
\text { Merchandise }\end{array}$ & 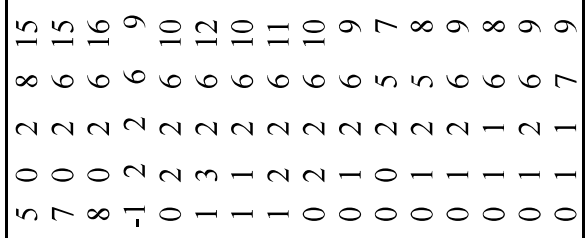 & 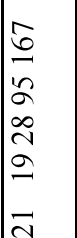 \\
\hline & & $\begin{array}{l}\text { TOTAL } \\
\text { Global } \\
\text { Economy } \\
\text { Traveler } \\
\text { Merchandise }\end{array}$ & 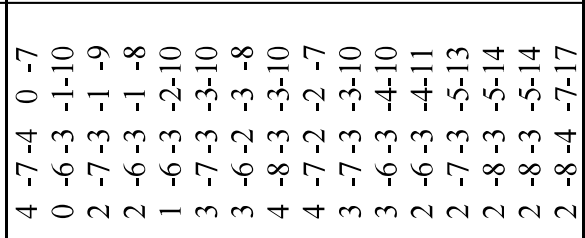 & 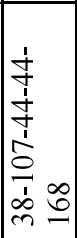 \\
\hline 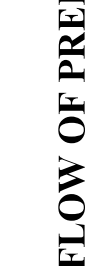 & 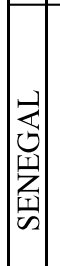 & $\begin{array}{l}\text { TOTAL } \\
\text { Global } \\
\text { Economy } \\
\text { Traveler } \\
\text { Merchandise }\end{array}$ & 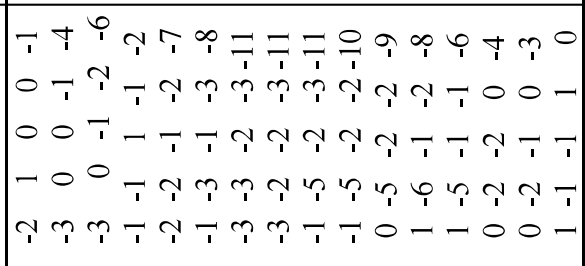 & 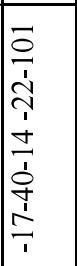 \\
\hline 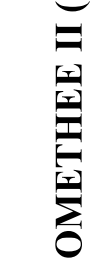 & 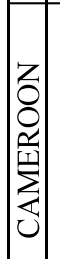 & $\begin{array}{l}\text { TOTAL } \\
\text { Global } \\
\text { Economy } \\
\text { Traveler } \\
\text { Merchandise }\end{array}$ & 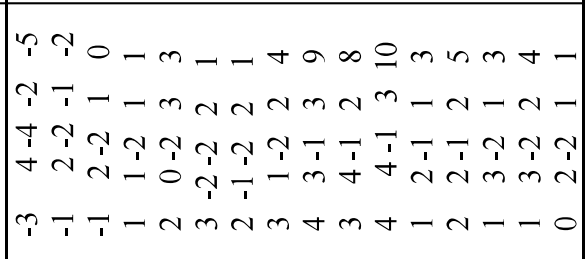 & 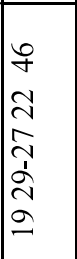 \\
\hline 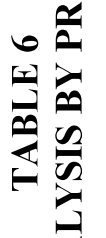 & $\mid$ & $\begin{array}{l}\text { TOTAL } \\
\text { Global } \\
\text { Economy } \\
\text { Traveler } \\
\text { Merchandise }\end{array}$ & 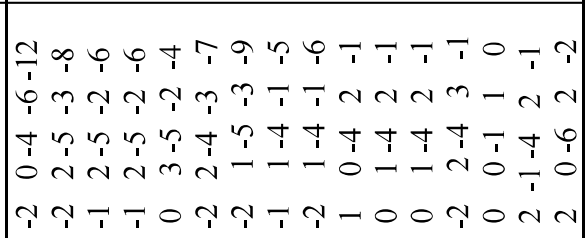 & $\mid \begin{array}{c}2 \\
1 \\
0 \\
1 \\
0 \\
0 \\
1 \\
0 \\
0 \\
1 \\
1\end{array}$ \\
\hline$\sum_{0}^{\sum_{0}^{Z}}$ & $\mid \begin{array}{l}z \\
\mathbf{z} \\
\mathbf{m} \\
\mathbf{m}\end{array}$ & $\begin{array}{l}\text { TOTAL } \\
\text { Global } \\
\text { Economy } \\
\text { Traveler } \\
\text { Merchandise }\end{array}$ & 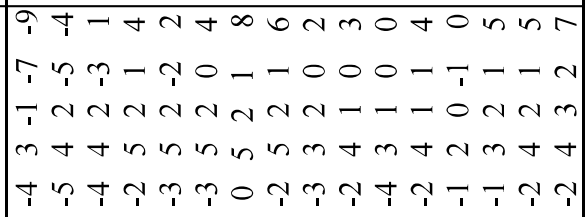 & 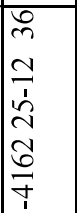 \\
\hline 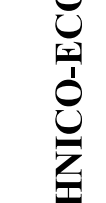 & 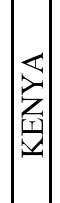 & $\begin{array}{l}\text { TOTAL } \\
\text { Global } \\
\text { Economy } \\
\text { Traveler } \\
\text { Merchandise }\end{array}$ & 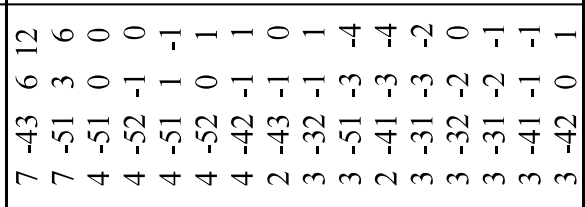 & 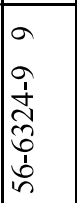 \\
\hline 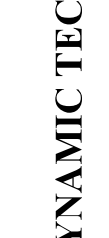 & 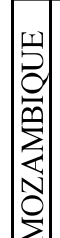 & $\begin{array}{l}\text { TOTAL } \\
\text { Global } \\
\text { Economy } \\
\text { Traveler } \\
\text { Merchandise }\end{array}$ & 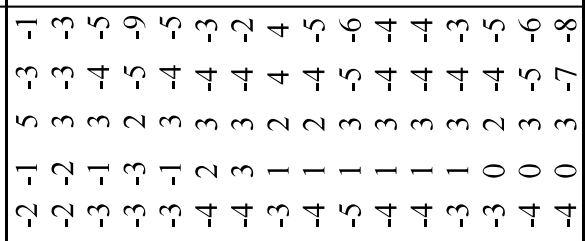 & $\mid \begin{array}{l}n \\
0 \\
1 \\
0 \\
0 \\
1 \\
+ \\
+ \\
+ \\
\infty \\
n \\
1\end{array}$ \\
\hline & $\mid \begin{array}{l}0 \\
0 \\
z \\
0 \\
0\end{array}$ & $\begin{array}{l}\text { TOTAL } \\
\text { Global } \\
\text { Economy } \\
\text { Traveler } \\
\text { Merchandise }\end{array}$ & 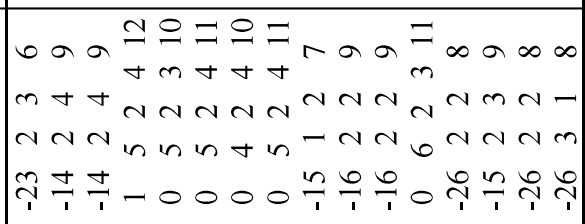 & 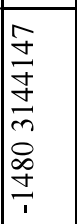 \\
\hline & & & 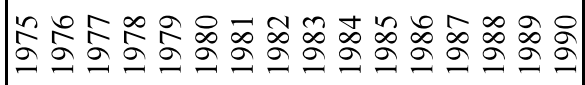 & $\exists$ \\
\hline
\end{tabular}




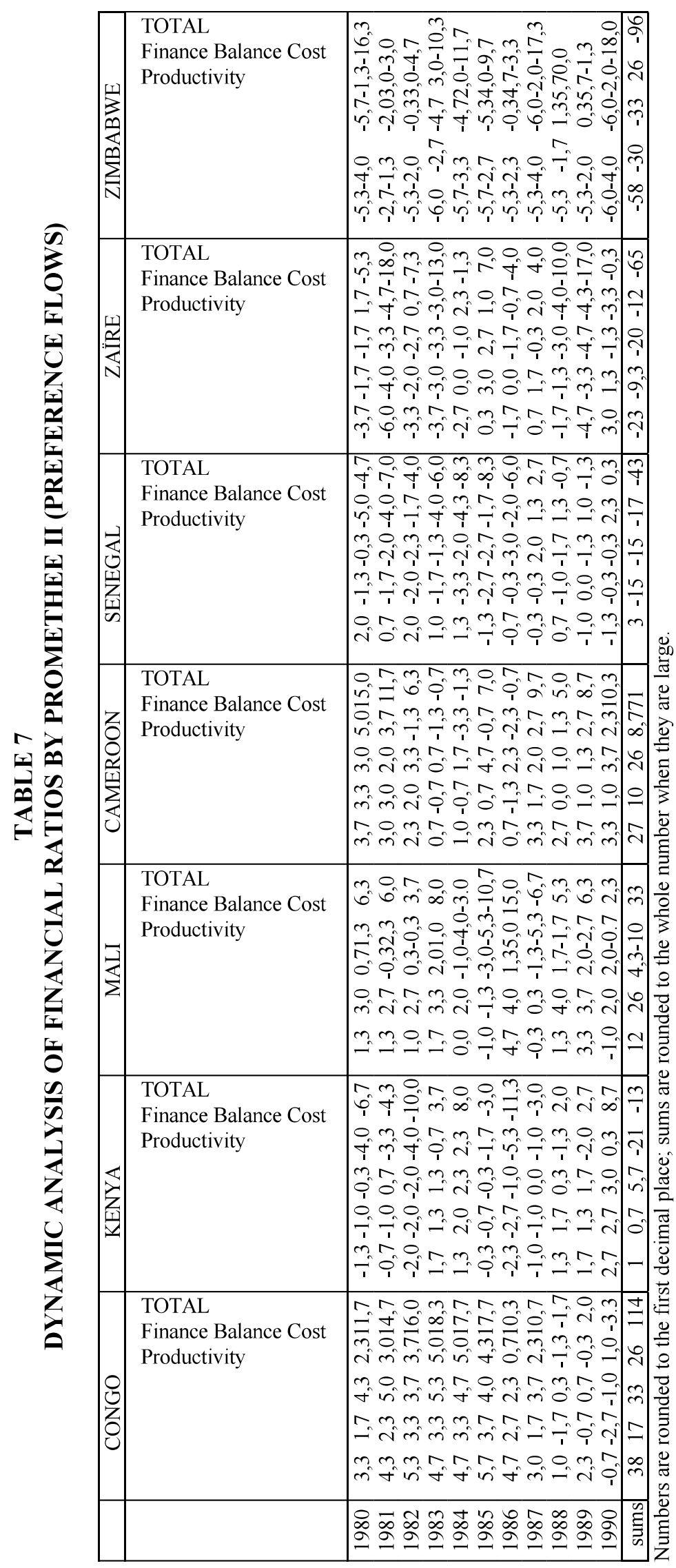




\section{Transversal Analysis of Financial Results}

Likewise, a comparison of the rankings provided by the two methods for financial analysis indicates that:

1. Overall, i.e. in aggregate financial terms, the ranking is identical with both approaches.

2. Within the aggregate assessment function, the PROMETHEE and ELECTRE rankings are very close, with the maximum downgrading found being three ranks out of one family for Mali.

3. In terms of financial efficiency, the results are identical with both methods, except that, according to PROMETHEE, Congo is effective on 3 families rather than 2, only at the "Cost" level where it now ranks 2nd instead of 3rd with ELECTRE. It can therefore be said that the position of the Congo is improving further according to PROMETHEE. The three effective countries are still Congo, Mali and Mozambique.

\section{Transversal Analysis of the Results on All Families of Criteria}

Some of the conclusions have already been stated. It should be pointed out, however, that Kenya and Senegal fall below the zero rating from a financial point of view according to PROMETHEE. It was also observed that Congo and Mozambique are effective for all families of criteria.

We also carried out a dynamic analysis of the relative positions of companies according to the two functions, using the aggregated flows of PROMETHEEII.

\section{Dynamic Analysis of the Related Positions of Companies According to the Two Functions}

By aggregating by sub-period the annual results of the PROMETHEE method, we have represented the positions of the six countries that have results on both axes and identified three sub-periods for the analysis of net flows for these six countries.

It should be pointed out that the comparisons were made respectively for the 7 countries listed in "Finance" and for the 9 countries listed in "Technico-economic "9. The sub-periods considered 1980-1983, 1984-1987, 1988-1990 do not therefore cover the sub-period 1975-1979, which has however been implicitly included in the technical-economic axis, since in finance there are only 11 years of observations. This representation enabled us to learn the following lessons.

Congo-Ocean Railways (CONGO). This company retained a leading position from 1975 to 1987, but its financial situation worsened over time and sharply in 88-90. Its technical and economic position improves in 80-83 and then deteriorates slightly. Its weakness in finance in 88-90 (flow $=-4$ ) is the only cause of a lack of continuous domination over all the other companies and especially over Cameroon, which is also very well placed.

The Cameroon National Railway Authority (CAMEROON). This company, which is as efficient as the one in Congo, is more financially stable than the latter. It is in a loop: its technical and economic situation improves in 84-87 at the expense of its financial situation, then the situation on both routes reaches in 8890 approximately that of $80-83$, which supposes a technical and economic deterioration in $88-90$ and a financial recovery compared to 84-87.

Kenyan Railways (KENYA). Over the whole period 80-90, the financial position improves, and more strongly at the end of the period (88-90). Its technical and economic situation, which was fairly good in 7579, deteriorated significantly in 84-87 and then improved slightly in 88-90.

The Mali Railway Company (MALI). The company improved steadily in technical and economic terms from 1975 to 1990, but in particular during the period 1984-87, which appears to have been at the expense of its deteriorating financial situation, but fortunately recovered in 1988-90.

The National Railway Company of Senegal (SENEGAL). The technical and economic situation deteriorated sharply in 80-83, only to improve significantly at the end of the period (88-90), just as it only recovered from its poor financial position at the end of the period (88-90).

The Zairian National Railway Company (ZAÏRE). From a financial point of view, the company, which had begun in the tail end, returned to it at the end of the period after a temporary improvement in 84-87, which brought it to the third position after those of Congo and Cameroon. On the technical and economic 
front, the situation, which was already bad in 1975-1979, is deteriorating more and more, especially at the end of the period (88-90).

\section{JUDGES}

Through the partial exploitation of this software, restricted to the analysis of its first two visuals, i.e. the tree of correlations of the judges and the "box-plot" of the six companies placed on the two axes, we have verified the more or less great dispersion of the judgements given by the 8 families of criteria (the 8 judges), thus bringing together in synthesis the two technical-economic and financial functions and all the years of observation.

\section{Interpretation of the Graph JUDGES}

In the first visual (Figure 3), we present the tree of rank correlations among the 8 families or judges of the six companies, obtained from a single linkage hierarchical clustering. First, we observe a perfect positive correlation between the "Traveller" and "Value Productivity" families on the one hand, and between "Overall" Performance and the small "Balance" on the other. These two pairs of families are furthermore linked to each other by a significant positive minimum correlation of 0.73 . This group of four families has a minimum positive correlation of 0.47 with the two families "Cost" and "Financial origin of resources", which are themselves correlated with each other by a coefficient of 0.47 . All six families are therefore more or less in accordance with each other. On the other hand, the "Merchandise" and "Economy" families tend to produce very different rankings from those provided by the other families (minimum coefficient of disagreement $=-0.33$ ). This pair itself shows a less severe disagreement between its two families (-0.06).

\section{FIGURE 3}

TREE OF MINIMUM CORRELATIONS OBSERVED BETWEEN THE 8 FAMILIES OF CRITERIA

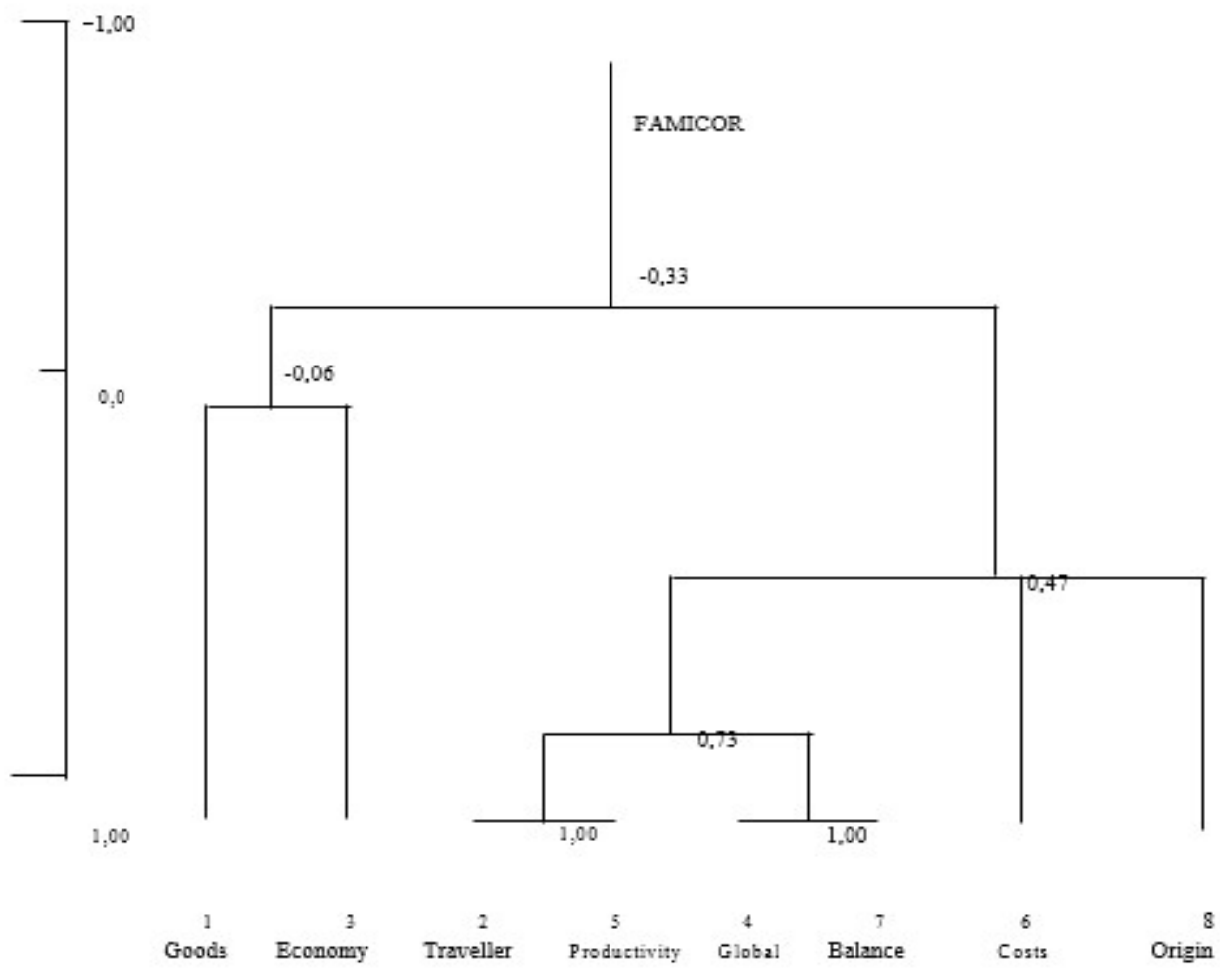


The second visual (Figure 4) shows the "box-plotting" of the six countries judged according to the 8 families. Let's consider the box from Mali, for example. The height of the box corresponds to the interval between the 1st and 3rd quartiles of the distribution of the (6) ranks attributable to this business by the 8 families (judges). The median of the distribution is at the level of the separation in the box. On either side of it, vertical lines connect it to the extreme rows expressed. The longer the box is, the more disagreement there is among the majority of family judges on the ranking of the country in question. It is therefore the company in Kenya that creates the most disagreement, reinforced by the two "stems" that reach the 1st and 6th ranks. On the other hand, the Congo company creates the least disagreement with a minimal box and only one family putting it in a bad position. Finally, the ranking of countries via the medians would provide: Congo 1st, Cameroon 2nd, Kenya and Mali tied, Senegal 5th and Zaire 6th. If one compares the companies in Mali and Kenya, the one in Mali should be better placed because it provokes a better agreement of the judges on its position, which can be seen by the smaller size of its box.

\section{FIGURE 4 \\ DISTRIBUTION OF THE RANKS ATTRIBUTED BY THE 8 FAMILIES TO 6 PUBLIC COMPANIES}

BOXPLOT

6

3

2

1
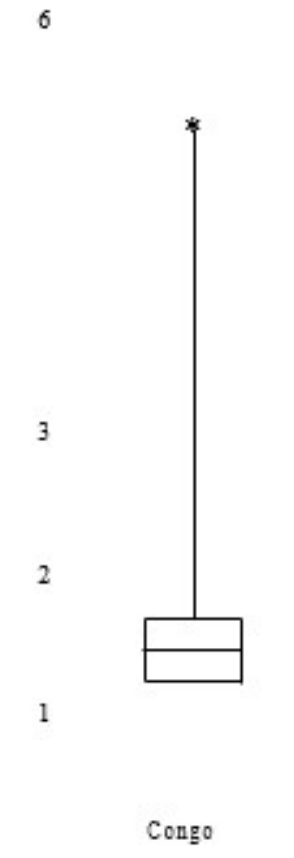

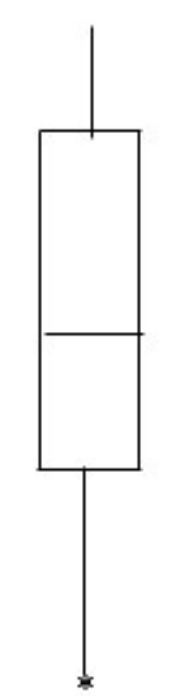

Kenys
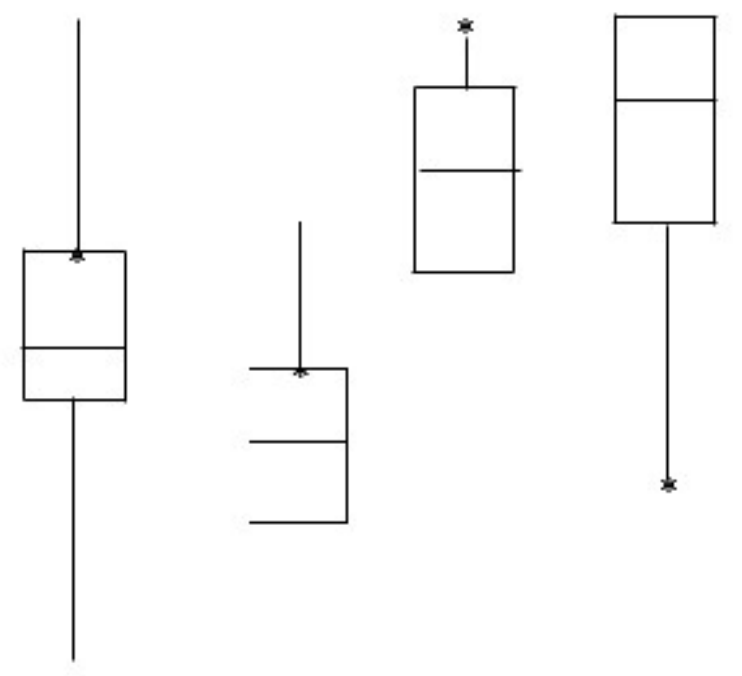

Mali
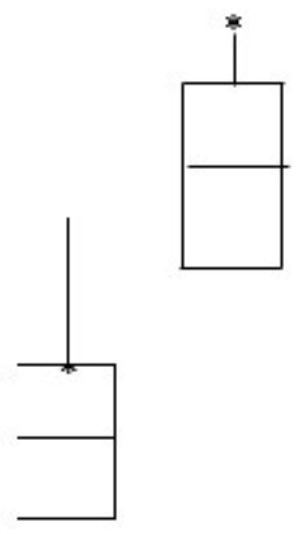

Cameroon Senegal
Zaire

\section{CONCLUSION}

A multi-criteria analysis of the public enterprises' performance is necessary because of the natural multiplicity of the often conflicting objectives pursued by these enterprises, which must be efficient like any other enterprise, but also serve the public and the economy of the countries they serve. Among the many existing multi-criteria methods, we have favoured three of them: ELECT I, of which we have created a new version, ELECTRE I-F (F for "frequential"), PROMETHY and JUDGES, which were moreover integrated in the same ARGOS software. Meanwhile, this software is organized to deal with the multicriteria and multi-judge problem in two stages, its Judges part overseeing the multi-criteria methods with a multi-judge approach. In the problem of classifying African railways, a hierarchy of criteria into families and then into two evaluation functions has been constructed to highlight the major objectives of this type 
of public service, which it is illusory to want to "optimise" in the classic single criterion sense of the term. In our study, the analyses of the relative positions of the railways and their evolution are, with some nuances, highly concordant when we compare the results of the ELECTRE I-F and PROMETHEE II methods, although they are mutually enriching. The multi-judge approach consists in considering that the families of criteria, which are the result of the aggregation of the lowest level, position themselves in the privileged points of view of the analysis to the extent that they can be given the name of judges of the performance of public enterprises. Regarding this, the final multi-judge analysis, proposed by "JUDGES", highlights the co-relationships (agreements and disagreements) between judges or families of criteria. The box plot diagram further synthesizes the converging or diverging opinions of these judges or families of criteria. Such an analysis of convergence/divergence of analytical views can be useful for policy makers.

\section{ENDNOTES}

1. ELECTRE I-F is a new version of ELECTRE I which uses the frequencies of presence or not in the annual kernels obtained from the application of the reciprocal graphs of ELECTRE I to each year of observation of the ratios, by family of criteria.

2. A careful analysis of this 3rd level was carried out in Mbangala's thesis, 1997.

3. The numerous tables of data and ratios and the details of the thresholds and scales of measurement chosen are given in Mbangala's (1997) thesis.

4. By naming companies more briefly by the name of their country, our purpose is to make the rather long names of these public companies more severe and meaningful, as these countries cannot be judged on the basis of a single company. Let the reader bear this in mind.

5. Due to lack of space this graphical representation is not presented here. G. Colson will send upon request the 3 graphs of this section and the next section.

6. It should be remembered that 9 companies are listed on the first axis and 7 on the second axis.

7. The term "effective" is understood in the multicriteria literature to mean.

8. We have included the annual flows from Tables 6 and 7 to make this representation, but weighted by a fraction that reflects the number of years in each sub-period or period analyzed.

9. Attention: the classification of the 6 countries based on the 8 families cannot obviously match other previous classifications provided for 9 or 7 countries judged on the basis of the two functions.

10. We have used the direct and reciprocal kernels of ELECTREI to classify, each year, 4characteristics of the railways, and the frequencies of these characteristics have been used to rank the railways, transforming there by this selection method into a selection and ranking method. We have avoided the ranking procedure supplied by ELECTRE II ,since it was deemed unsuitable for annual qualification purposes. We call our new procedure ELEC-TREI-F, F meaning Frequency of belonging or not to the kernels of ELECTREI.

\section{REFERENCES}

Directory of African Railways (Yearbook of African Railways). (1988). Africarail, Christian Scasso, Paris.

Brans, J-P., Vincke, P., \& Mareschal, B. (1986). How to Select and to Rank Projects: The Promethee Method. E.J.O.R., 24(2), 228-238.

Colson, G. (2000). The OR's Prize Winner and the Software ARGOS: How a Multijudge and Multicriteria Ranking GDSS Helps a Jury to Attribute a Scientific Award. Computers \& Operations Research, 27(7-8), 741-755.

Colson, G., \& De Bruyn, C. (1989). Editorial on Models and Methods in Multiple Objective Decision Making, Pergamon Press, Oxford. Reproduit in: Mathematical and Computer Modelling, 12(10/11), 1201-1220.

Colson, G., \& Mareschal, B. (1994). JUDGES: A Descriptive Group Decision Sup-port System for the Ranking of Items. Decision Support Systems, 12, 391-404.

Maystre, L.Y., Pictet, J., \& Simos, J. (1994). Multi-criteria methods ELECTRE. Presses Politecnics and Universities of Romandes, Lausanne. 
Mbangala, M. (1997). Multiple targets and performance measures for public companies in developing countries. The case of railways in sub-Saharan Africa. PhD, Université de Liège, Liège.

Roy, B. (1985). Multi-criteria decision support methodology. Economica, Paris.

Schärlig, A. (1996). Practice ELECTRE et PROMETHEE. Polytechnic and University Presses Romandes, Lausanne.

Vincke, P. (1989). Multi-criteria decision-making aid. Éditions Ellipses, Brussels. 


\title{
LONG SUMMARY
}

\section{Multicriteria Analysis of Public Railways Performances}

\author{
Gerald Colson \\ University of Liège \\ Mapappa Mbangala \\ University of Liège
}

Sections $1 \& 2$. Assessment of a public utility's performance is naturally multicriteria due to its dual mission of efficiency and effectiveness as a public service and instrument of economic development, both of them requiring a consistent set of several indicators. Nine railway companies, one per country, are pair wise ranked according to two evaluation functions, using the following multicriteria methods:

ELECTREI-F11, PROMETHEE II and JUDGES. The two evaluation functions of effectiveness and financial ratios efficiency ratios included are the top level of a hierarchy of criteria. At the bottom, 25 criteria valued on a ratio scale capture single classical measures of technical effectiveness (freight and passenger traffic market shares, traffic densities, etc.), efficiencies and other financial performances (operating rate, self-financing ratios, etc.). At the intermediate level, the criteria are gathered into 8 families, also called "judges", since these families play the role of decision makers in the ranking process. Primary and incomplete data about the companies were collected not without difficulty. Annual data for nine railways over the1975-1990 period were available for estimating their technico-economical performance (=First axis of evaluation). Seven railways, six of which are common to the first group, provided annual data extending over the 1980-1990 period which were used to evaluate their financial ratios (=Second axis of evaluation). Quasi-criteria were selected, the thresholds of which were computed taking into account the proximity of some evaluations preventing the corresponding railways to be discriminated on the considered criterion (see Tablel for a list of criteria and their thresholds).

Section3. The methodology of this study (see Figurel for a summary) consists in drawing longitudinal sections and cross summaries through the data to appraise the dynamics of the companies' relative positions and their average behavior across the periods.

First ELECTREI is used to make pair wise comparisons of the national companies for each criterion and year. Then the kernel (N) of "good and incomparable" companies results from the aggregation procedure applied successively to each family, using a concordance threshold of $C=0.75$. No discordance test is considered useful in our analysis. The reciprocal kernel ( $N$ ') is obtained, thus providing theset of "bad and incomparable" companies for each family. Combining the kernels, we get four classes of companies: the incomparable (C) are in the kernels' intersection, the "good" (B) are in $N \mid C$ and the "bad" in N'|C while the "mean" ones (M) are in E (see Figure 2). A novelty in the ELECTREI methodology is to codify the four qualifications as follows: $M=2, C=0, E=1$ and $B=2$, in order to evaluate the frequencies of classes $M$, $C, E, B$ (seep.54), and a compensated score for each firm for the whole period (see Tables 2 and 3). Consideration of these yearly qualifications produces the longitudinal analyses presented in Tables 4 and 5, which cope with the dynamics of the companies' classes throughout the periods, along the two axes of evaluation. The synthetic cross analyses provided by the totals given in Tables 2 and 3 provide a bidimensional graph which is the best picture of the relative position of each national company according to the two global evaluation functions. Essentially our measures allow us to qualify our multi criteria rankings for each national company. In the end, by applying common rules of efficiency to the set of national railways on each of four evaluation functions, we conclude that the railways of Congo, Cameroun, Maliand 
Zimbabwe are financially efficient whilst those of Zambia, Congo, Kenya and Mozambique are technicoeconomically efficient.

PROMETHEEII: we follow the same methodology as in ELECTREI. Tables 6 and 7 are equivalent to Tables 2 and 3. They provide the sums of annual net flows of preference per country and per family of criteria. Then, proceeding to a cross analysis of the technico-economical and of the financial ratios flows, we find that these of efficient countries are the same for ELECTRE and PROMETHEE, while the differences in ranks in side each evaluation function are rare and weak. In fact, small changes are observed. For example, in financial terms, Kenya and Senegal are positioned lower than zero if we use PROMETHEE instead of ELECTRE.

The dynamics of the results supplied by PROMETHEEII are studied using data from the following subperiods: 1980-83, 1984-87, 1988-90. We observe that the relative financial performance of the Congolese railway falls during the $88-90$ period while Kenya's improves.

The JUDGES software is explored partially: only the first two visual aids are used (Figures 3 and 4). Figure 3 shows the single linkage clustering hierarchy providing the tree of rank correlations between the eight families or judges of our analysis. Mainly, we observe a perfect correlation between "Passenger" and "Productivity" and another perfect correlation between "Global performance" and "General financial performance". The disagreement between the pair of families: "Freight and Economy" and the rest of families of criteria is not able too. The JUDGES' second visual aid (Figure 4) is the box-plotting of the six common national railways judged by the 8 families. The greater the vertical length of the box, the greater the disagreement between the rankings of the 8 families. For instance, the Kenyan railway causes the biggest disagreement. Among the judges (families), the Congo's railway encounters the least disagreement. 